\title{
Contribuições da pesquisa-ação para a Educação Inclusiva
}

\section{Contributions of Action Research to Inclusive Education}

\author{
Márcia Cristina Florêncio Fernandes Moret ${ }^{1}$, Lívia Catarina Matoso dos Santos Telles ${ }^{1 *}$, \\ Marlene Rodrigues ${ }^{1}$, João Guilherme Rodrigues Mendonça ${ }^{1}$
}

\begin{abstract}
RESUMO
A pesquisa-ação é um método que consiste em elucidar problemas sociais e técnicos, cientificamente relevantes, por intermédio de grupos de pesquisadores e interessados que buscam a resolução de problemas ou transformação de uma realidade. Objetiva-se o aprofundamento de reflexões sobre as possíveis contribuições da pesquisa-ação como instrumento pedagógico e científico na Educação Inclusiva, buscando transformar as ações de segregação em ações de inclusão. Para tanto, como metodologia, assume-se uma perspectiva qualitativa, por meio da revisão bibliográfia sobre a temática em questão, apresentando como resultados a importância da pesquisa-ação na construção de práticas e ações inclusivas no ambiente escolar. No campo educacional, a pesquisa-ação tem impactos positivos no processo ensino e aprendizagem dos alunos(as), além de trazer contribuições para o desenvolvimento de uma educação emancipadora. É possível realizar intervenção na realidade, possibilitando novos olhares para os problemas enfrentados pelos estudantes público-alvo da Educação Especial, oportunizando desenvolvimento social, político, crítico e acadêmico.
\end{abstract}

Palavras-chave: Pesquisa-ação; Educação Inclusiva; Ensino; Aprendizagem.

\section{ABSTRACT}

Action research is a method that consists of elucidating scientifically relevant social and technical problems through groups of researchers and other interested people who seek to solve problems or transform a reality. The objective is to deepen reflections on the possible contributions of action research as a pedagogical and scientific instrument in Inclusive Education, seeking to transform segregating actions into inclusive actions. Therefore, as a methodology, a qualitative perspective is assumed, through literature review on the subject in question, presenting as results the importance of action research in the formation of inclusive practices and actions in the school environment. In the educational field, action research has positive impacts on the teaching and learning process of students, in addition to bringing contributions to the development of an emancipatory education. It is possible to intervene in reality, enabling new perspectives on the problems faced by students who are the target audience of Special Education, providing opportunities for social, political, critical and academic development.

Keywords: Action research; Inclusive education; Teaching; Learning.

\footnotetext{
${ }^{1}$ Universidade Federal de Rondônia (UNIR)

*E-mail: livia.santos@ifro.edu.br
} 


\section{INTRODUÇÃO}

Nas últimas décadas, a pesquisa-ação vem crescendo e se destacando em diversas áreas de pesquisa. Esse crescimento é justificado pelo vasto mosaico de abordagens teóricometodológicas que a pesquisa-ação possui. Segundo Franco (2005, p.3) essa abordagem, "instiga a reflexão sobre sua essencialidade epistemológica e sobre as possibilidades como práxis investigativas".

Quando falamos em pesquisa-ação e sua aplicabilidade, destacamos que ela está voltada para diversificadas aplicações em diferentes áreas de atuação como: educação, comunicação social, serviço social, organização, tecnologia e práticas políticas e sindicais (THIOLLENT, 2011).

A pesquisa-ação é um tipo de pesquisa social com base empírica, concebida e realizada com associação de uma ação ou com a resolução de um problema coletivo no qual os pesquisadores e os participantes da situação ou do problema estão envolvidos de modo cooperativo ou participativo (THIOLLENT, 2011).

Partindo dessa premissa, a pesquisa-ação requer uma intervenção na realidade para tentativa de melhoria de alguma situação ou problema. Essa pesquisa deve ser concebida como método, onde são usados procedimentos que unem o conhecimento e ação, logo, produz novos conhecimentos.

Thiollent (2011, p.86) corrobora com a afirmação de que o objetivo da pesquisa-ação é a "resolução de problemas e a transformação de uma realidade", tornando-se necessário que os pesquisadores levem em conta os aspectos comunicativos na espontaneidade e no planejamento consciente de ações transformadoras.

O pesquisador em pesquisa-ação não é nem um agente de uma instituição, nem um ator de uma organização, nem um indivíduo sem atribuição social; ao contrário, ele aceita eventualmente esses diferentes papéis em certos momentos de sua ação e de sua reflexão. Ele é antes de tudo um sujeito autônomo e, mais ainda, um autor de sua prática e de seu discurso (BARBIER, 2004, p. 19).

Nessa visão, a pesquisa-ação é uma estratégia para o desenvolvimento de pesquisadores e educadores, que utilizarão suas pesquisas na melhoria de suas práticas e consequentemente transformação de sua realidade. No campo educacional, essas pesquisas contribuirão para melhoria do processo ensino e aprendizagem, além de oportunizar novos olhares e reflexões sobre a práxis pedagógica.

Tripp (2005, p.445) diz que "a pesquisa-ação educacional é principalmente uma estratégia para o desenvolvimento de professores e pesquisadores de modo que eles possam utilizar suas pesquisas para aprimorar seu ensino e, em decorrência, o aprendizado de seus alunos [...]”. 
O presente trabalho aprofunda reflexões sobre a pertinência e as possibilidades da pesquisa-ação como instrumento pedagógico e científico na Educação Inclusiva, buscando assim responder às questões: Quais as possíveis contribuições da pesquisa-ação para Educação Inclusiva? Como transformar as ações de segregação em ações inclusivas?

Carvalho (2004, p.50) diz que a educação, na perspectiva da inclusão “[...] é a própria vida que flui, devendo possibilitar, do ponto de vista político, ético e estético, o desenvolvimento da sensibilidade e da capacidade crítica e construtiva dos alunos-cidadãos.”

Na metodologia assume-se uma perspectiva qualitativa, por meio da revisão bibliografia sobre a temática em questão, apresentando como resultados a importância da pesquisa-ação na construção de práticas e ações inclusivas no ambiente escolar.

\section{RESULTADOS E DISCUSSÕES}

A pesquisa-ação trata-se de uma metodologia bastante adequada para atender demandas pontuais, que necessitam de uma ação ou intervenção sobre a realidade/problema. Como trata-se de uma pesquisa que não limita o pesquisador em suas investigações e que o oportuniza a desempenhar um papel ativo na realidade dos fatos observados, destacamos a importância da pesquisa-ação como instrumento facilitador para a Educação Inclusiva.

A inclusão se refere a um sentimento cultural e ambiental de pertencimento, podendo ser avaliado por meio da forma como os sujeitos são valorizados, respeitados, aceitos e incentivados a participar totalmente das ações.

Inclusão é a nossa capacidade de entender e reconhecer o outro e, assim, ter o privilégio de conviver e compartilhar com pessoas diferentes de nós. A educação inclusiva acolhe todas as pessoas, sem exceção. É para o estudante com deficiência física, para os que têm comprometimento mental, para os superdotados, para todas as minorias e para a criança que é discriminada por qualquer outro motivo. Costumo dizer que estar junto é se aglomerar no cinema, no ônibus e até na sala de aula com pessoas que não conhecemos. Já inclusão é estar com, é interagir com o outro. (MANTOAN, 2005, p.24)

Sabemos que a inclusão ainda é um desafio para a educação e quando analisamos a realidade encontrada nas escolas brasileiras, nos entristecemos ao ver as dificuldades enfrentadas pelos estudantes público-alvo da Educação Especial (EPAEE) e as barreiras impostas para se ter acesso à educação. Essas dificuldades trazem impacto direto no processo de ensino e aprendizagem, pois limita a construção da aprendizagem e o desenvolvimento integral desses estudantes.

Quando falamos no processo educativo do aluno com deficiência, precisamos elencar a trajetória histórica e as fases educacionais que essa educação perpassou até chegar aos dias atuais. Segundo Sassaki (2002, p.3) as fases foram: exclusão, segregação, integração e inclusão. 
Fase de exclusão - Nesta fase, nenhuma atenção educacional foi provida às pessoas com deficiência. Estas eram consideradas indignas de educação escolar.

Fase de segregação institucional — Por absoluta impossibilidade de acesso às escolas comuns por parte das crianças e jovens com deficiência, suas famílias se uniram para criar escolas especiais. Hospitais e residências eram também utilizados como locais de Educação Especial.

Fase de integração - Crianças e jovens mais aptos eram encaminhados às escolas comuns, classes especiais e salas de recursos.

Fase de inclusão - Todas as pessoas sãs incluídas nas salas comuns. Os ambientes físicos e os procedimentos educativos são adaptados para acomodar a diversidade do alunado. As escolas levam em consideração as necessidades de todos os alunos.

Sabemos que todas as fases anteriores a inclusão oprimiam as pessoas com deficiência, além de lhes tirar o acesso ao seu direito básico e constitucional que é a educação. Sabendo ainda que muitas pessoas com deficiência pertencem a camadas mais pobres da população, sendo privadas de outros direitos constitucionais, muitas vezes perdem acesso ao básico que é ter acesso aos bancos escolares.

Quando conhecemos essa trajetória de sofrimento e de fata de oportunidades, refletimos sobre o Art. $3^{\circ}$, inciso IV da Constituição Federal (1988) que estabelece como objetivos fundamentais do Estado brasileiro, "[...]promover o bem de todos, sem preconceitos de origem, raça, sexo, cor, idade e quaisquer outras formas de discriminação".

Nessa trilha de discussão, a pessoa com deficiência representa um importante desafio a ser enfrentado pelo Estado, na proteção e acesso a seus direitos já defendidos na Constituição Federal (1988). Isto porque questões socioculturais, políticas e econômicas influenciam na efetivação de políticas públicas eficazes para o atendimento das necessidades vivenciadas por essas pessoas.

Devemos destacar que um dos grandes desafios enfrentados pela pessoa com deficiência é o acesso à educação. Nessa perspectiva, elencamos a necessidade de um novo olhar sob a perspectiva inclusiva, pois sabemos as dificuldades, limitações e prejuízos vivenciados por essas pessoas, principalmente as que estão em situação de vulnerabilidade social.

Quando falamos nos direitos estabelecidos em lei, evidenciamos as vias paralelas pelas quais esse processo ocorre: de um lado temos as ideologias da lei e o respeito garantido, na contramão vemos as dificuldades e enfrentamentos de crianças e adolescentes na busca pelo acesso a esses direitos.

No caso das pessoas com deficiência, um dos complicadores apontados pela sociedade para sua entrada e permanência na escola é a aceitação da deficiência e das necessidades educacionais específicas. Sabemos que apesar da inclusão escolar ser defendida e garantida pela legislação vigente, ainda não é plenamente efetivada nas escoas brasileiras, há muito a ser feito para que efetivamente seja praticada nas escolas. 
Nessa visão, entender o que se passa dentro do contexto escolar, como é vista à educação desses estudantes, quais estratégias e metodologias são utilizadas para o ensino, como é a atuação e formação dos docentes que atuam com esse público, nos permite entender as contribuições da pesquisa-ação como instrumento facilitador para a Educação Inclusiva, uma vez que esse tipo de pesquisa oportuniza aos protagonistas da situação: ação, reflexão e busca de melhorias da realidade.

Sassaki (2002, p.5) afirma que na filosofia da inclusão "[...] a sociedade deve ser modificada a partir do entendimento de que ela é que precisa ser capaz de atender às necessidades de seus membros e o desenvolvimento dos deficientes por meio da educação deve ocorrer dentro do processo de inclusão e não como um pré-requisito".

\begin{abstract}
O princípio fundamental da escola inclusiva é o de que todas as crianças deveriam aprender juntas, independentemente de quaisquer dificuldades ou diferenças que possam ter. As escolas devem reconhecer e perceber a importância de se trabalhar com as diferenças linguísticas, de gênero, de etnias, sociais e tantas outras. Tais diversidades enriquecem o currículo escolar contribuindo para a formação de sujeitos altruístas e consequentemente de uma sociedade mais humanitária, justa e resiliente. [...] (MENEZES; SANTOS, 2001.p. 3).
\end{abstract}

Desse modo, frisamos que a Escola deve ser pensada para todos e todas, voltada para os valores humanos, o que significa dizer que a escola deve se adequar para atender a necessidade do estudante, permitindo uma transformação social, acreditando nas diferentes possibilidades e nos diferentes caminhos que cada um traça para a construção da aprendizagem, que possibilite a convivência e o reconhecimento do outro em todas as suas dimensões. Mantoan (2003, p.12) afirma que:

\begin{abstract}
A escola não pode continuar ignorando o que acontece ao seu redor nem anulando e marginalizando as diferenças nos processos pelos quais forma e instrui os alunos. E muito menos desconhecer que aprender implica ser capaz de expressar, dos mais variados modos, o que sabemos, implica representar o mundo a partir de nossas origens, de nossos valores e sentimentos.
\end{abstract}

Partindo dessa trilha, a pesquisa-ação colabora significativamente para melhoria e avanço da educação e da inclusão, pois traz uma relação entre conhecimento e ação, tanto do campo do agir, quanto do campo do fazer, haja vista seu imensurável alcance de transformação, sendo capaz de alcançar realizações, ações efetivas ou mudanças no campo social e no processo formativo do aluno público-alvo da Educação Especial, além de ter função política valorativamente inserida na perspectiva da política transformadora, pois possui: planejamento flexível, metas, prioridades, negociação, moralidade, sendo possível difundir a avaliação dos resultados pelos participantes e pelos pesquisadores da pesquisa. 
Segundo Tripp (2005, p. 445-446) é importante que se reconheça a pesquisa-ação como um dos inúmeros tipos de investigação-ação "[...], na qual se aprimora a prática pela oscilação sistemática entre agir no campo de prática e investigação".

Quando nos referimos a pesquisa-ação para melhoria do processo inclusivo, evidenciamos ainda que é capaz de promover novos olhares, compreensões e ofertar estratégias e metodologias para melhoria do processo ensino e aprendizagem, na formação de professores, sendo assim, um importante elemento na construção de novas práxis inclusivas, pois pretende-se resolver problemas identificados na realidade escolar como também a constante avaliação dos pesquisadores em relação às ações planejadas.

A pesquisa-ação ultrapassa a ação ativa do pesquisador, pois traz aumento do conhecimento do pesquisador e aumenta o nível de consciência de todos os envolvidos na pesquisa.

Nessa perspectiva, a proposição da pesquisa-ação é contribui com a formação de professores reflexivos, que pensem sobre suas práxis, que analisam seus erros e acertos, logo, que busquem melhorias no processo ensino e aprendizagem e ainda promovam mais acessibilidade e inclusão. Portanto, "terão de aprender a refletir sobre suas próprias teorias tácitas, [...] sobre os métodos de investigação, [...] sobre as teorias e os processos que eles trazem para sua própria reflexão-na-ação" (SHON, 2000, p. 23).

Quando elucidamos as contribuições da pesquisa-ação para Educação Inclusiva, nos justificamos exatamente na afirmação de Shon (2000) quando traz a importância da reflexão na ação, pois a reflexão realizada no ato da ação, proporciona uma ampla aproximação do professor com o problema ou necessidade apresentada.

A reflexão durante a ação permite compreender criticamente o processo e o que está acontecendo no calor da ação. Assim, a reflexão-na-ação tem uma função crítica, questionando a estrutura de pressupostos do ato de conhecer na ação: "Pensamos criticamente sobre o pensamento que nos levou a essa situação difícil ou essa oportunidade e podemos, neste processo, reestruturar as estratégias de ação, as compreensões dos fenômenos ou as formas de conceber os problemas." (SHON, 2000, p. 33)

$\mathrm{O}$ autor afirma ainda que a reflexão-na-ação ocorre no ato de conhecer na ação. $\mathrm{O}$ problema ou necessidade se apresenta e neste momento o professor refletirá em torno do que seria necessário fazer para solucioná-lo. Assim, o professor acaba por dialogar com a situação que está ocorrendo, buscando solucionar os problemas que surgiram

Na educação, a reflexão na ação e sobre a ação conduz à transformação e reformulação das práticas, assim como o aprofundamento e a construção de fundamentos teóricos para a sustentação da prática.

Nesse sentido, afirmamos a relevância da pesquisa-ação na educação, pois apresenta todas as caraterísticas já apresentadas por Shon (2000), além de que a pesquisa-ação não é constituída 
apenas para ação ou participação de pesquisadores e envolvidos, ela também produz conhecimento a partir das reflexões dos sujeitos que observaram uma ação, que buscaram novas práticas e estratégias, além de proporcionar uma estreita relação entre o conhecimento e a ação. Assim, essa pesquisa aponta que essa relação só é possível quando ocorre tanto no campo do agir, quanto no campo do fazer.

Tripp (2005, p.447) afirma que a pesquisa-ação, tanto nas áreas da prática quanto nas áreas da pesquisa, terá características tanto prática rotineira quanto da pesquisa científica, isso porque tem como finalidade alcançar transformações, função política e de valores, pois propõe alcançar realizações, ações efetivas e mudanças sociais, sendo possível através da reflexão das ações, da vivência de um problema e busca de melhorias de tal realidade.

Baseados nessa afirmativa, Thiollent (2011, p.62) corrobora apontando que quanto aos problemas colocados inicialmente de ordem prática, tratam de procurar soluções para se chegar a alcançar um objetivo ou realizar uma possível transformação dentro da situação observada, deve ser pensado da seguinte forma:
a) análise e delimitação da situação inicial;
b) delineamento da situação final, em função de critérios de desejabilidade e de factibilidade;
c) identificação de todos os problemas a serem resolvidos para permitir a passagem de (a) a (b);
d) planejamento das · ações correspondentes;
e) execução e avaliação das ações (THIOLLENT, 2011, p.62).

Portanto, toda ação proposta através da pesquisa-ação vai requerer análise dos resultados, das ações feitas a partir dessa proposta, o que consequentemente oportunizará mais reflexão sobre a ação.

Na perspectiva da Educação Inclusiva, a maior estratégia ofertada pela pesquisa-ação é o plano de ação, sendo esse uma das fases da pesquisa. O plano de ação, fará com que seja pensando nos saberes científicos e a experiência prática, ou seja os dois universos culturais: dos especialistas e dos interessados, pois farão a comunicação para estabelecer melhorias na ação e consequentemente no processo ensino e aprendizagem dos alunos público-alvo da educação inclusiva.

Segundo Thiollent (2011, p.79-80) o plano de ação vai consistir ainda em definir com precisão:

a) Quem são os atores ou as unidades de intervenção? b) Como se relacionam os atores e as instituições: convergência, atritos, conflito aberto? c) Quem toma as decisões? d) Quais são os objetivos (ou metas) tangíveis da ação e os critérios de sua avaliação? e) Como dar continuidade à ação, apesar das dificuldades. f) Como assegurar a participação da população e incorporar suas sugestões? g) Como controlar o conjunto do processo e avaliar os resultados?”. 
Todavia, destacamos que para que haja sucesso na execução do plano de ação é preciso que todos os envolvidos na pesquisa tenham o mesmo objetivo, que é a busca por melhores condições de inclusão e melhor qualidade no processo ensino e aprendizagem.

Quando firmado esse compromisso e comprometimento, todas as fases da pesquisa-ação serão de fundamental importância para construção de uma nova realidade, pois todas as ações e reflexões serão pautadas para a promoção de uma escola efetivamente inclusiva, que respeite a singularidade e a diferença de seus alunos, que proponha e busque alternativas para melhoria da construção do conhecimento e assim forme cidadão capazes e competentes a atuarem na área que escolherem seguir e para vivência social.

Cabe destacar ainda que a pesquisa-ação traz com especificidades o relacionamento entre os objetivos práticos e do conhecimento, como referido por Thiollent (2011, p.24) :

a) objetivo prático: contribuir para o melhor equacionamento possível do problema considerado como central na pesquisa, com levantamento de soluções e proposta de ações correspondentes às "soluções" para auxiliar o agente (ou ator) na sua atividade transformadora da situação. É claro que este tipo de objetivo deve ser visto com "realismo", isto é, sem exageros na definição das soluções alcançáveis. Nem todos os problemas têm soluções a curto prazo.

b) objetivo de conhecimento: obter informações que seriam de difícil acesso por meio de outros procedimentos, aumentar nosso conhecimento de determinadas situações (reivindicações, representações, capacidades de ação ou de mobilização etc.)."

Para o autor, quanto maior o conhecimento produzido na pesquisa, mais assertiva será a ação que se propõe, ressaltando a importância do equilíbrio entre as duas perspectivas. A pesquisa-ação não é só ação, com ela deve-se alargar o conhecimento da situação, aprofundar os debates e avançar em relação aos problemas apresentados. Consequentemente, toda ação reflete na sala de aula e no processo formativo dos alunos, uma vez que o eixo central da pesquisa-ação é a transformação de um problema existente na realidade escolar.

Corroborando com essa afirmativa, Tripp (2005) aponta que a pesquisa-ação não apenas compreende a prática de modo a melhorá-la, mas também se ganha melhor compreensão da prática rotineira. Logo, essa compreensão traz o aprimoramento para a transformação e consequentemente impactos positivos para escola e para o processo formativo.

Nesse viés apontamos que a pesquisa-ação vai contribuir ainda na transformação das ações de segregação em ações inclusivas, isso porque, segundo Thiollent (2011, p.22-23) a pesquisa-ação possui uma ampla e explicita interação entre pesquisadores e pessoas implicadas na investigação, prioriza os problemas e soluções efetivando uma ação concreta, tem como objeto de investigação situações sociais e problemas encontrados.

Seu objetivo é resolver ou esclarecer problemas e situações observadas, fazer o acompanhamento dos envolvidos em todas as ações, decisões e atividades da pesquisa e ainda 
não se limita a uma forma de ação e sim pretende-se aumentar o conhecimento dos pesquisadores e das pessoas e grupos considerados.

Ainda segundo o autor, os objetivos de conhecimento potencialmente alcançáveis serão:

a. Coleta de informação original acerca de situações ou de atores em movimento.

b. A concretização de conhecimentos teóricos, obtida de modo dialogado na relação entre pesquisadores e membros representativos das situações ou problemas investigados.

c. A comparação das representações próprias aos vários interlocutores, com aspecto de cotejo entre saber formal e saber informal acerca da resolução de diversas categorias de problemas.

d. A produção de guias ou de regras práticas para resolver os problemas e planejar as correspondentes ações.

e. Os ensinamentos positivos ou negativos quanto à conduta da ação e suas condições de êxito.

f. Possíveis generalizações estabelecidas a partir de várias pesquisas semelhantes e com o aprimoramento da experiência dos pesquisadores. (THIOLLENT, 2011, p. 45)

Entendemos, assim como Thiollent (2011), que a pesquisa-ação consiste na elucidação de problemas de cunho social e técnico e de relevância científica que conta com diferentes atores interessados na resolução dos problemas identificados em contextos específicos.

É preciso pensar ainda que o processo de inclusão deve ser conduzido de forma a apontar caminhos e práticas que oportunizarem professores(as) e alunos(as) no processo de ensino e aprendizagem. Desse modo, a educação deve ser pensada com todos e para todos.

É importante destacar que a Educação Inclusiva constitui um paradigma fundamentado nos direitos humanos e defende os alunos de forma igualitária, onde todos devem ter o mesmo tipo de educação, ou seja, educação de qualidade.

A visão dos direitos humanos tem como conceito a cidadania fundamentada no reconhecimento das diferenças, que significa respeitar o próximo conforme a sua deficiência ou necessidade.

Partindo desse pressuposto, a pesquisa-ação contribuirá para que todas as ações segregadoras sejam extinguidas, trazendo essa mudança através da proposta de reflexão sobre a ação, logo, a inclusão de fato será mais efetiva nas escolas e consequentemente os reflexos dessas ações contribuirão no desenvolvimento educacional dos alunos deficientes.

Portanto, a pesquisa-ação oportunizará novos paradigmas sobre a inclusão, sendo capaz de modificar as estruturas excludentes existentes na escola e conduzir ações inclusivas que oportunize todos os alunos independente de sua limitação ou deficiência.

\section{CONSIDERAÇÕES FINAIS}

Diante do exposto, conclui-se que a pesquisa-ação pode ser uma metodologia muito eficiente pois contribui como ferramenta na construção de uma escola inclusiva. Sua contribuição 
se dá a partir das reflexões sobre a ação, da formação e preparo do professor, na busca por melhoria em sala de aula, na busca de novas de práxis pedagógicas, estratégias e metodologias de ensino, sobretudo melhorias no processo formativo do aluno, visto que toda reflexão sobre a ação gera novas ações.

Nessa perspectiva, a pesquisa-ação fomenta novos olhares e práticas que respeitem as peculiaridades e singularidades dos alunos público-alvo da Educação Especial, além de lhes oportunizar mais acessibilidade e qualidade no processo formativo.

A pesquisa-ação é flexível, permitindo aos envolvidos e pesquisadores alterar ações, práticas, realizarem análises mais profundas das fases da pesquisa e consequentemente fomentar melhorias no processo ensino e aprendizagem e no problema de pesquisa.

Ressalta-se que a pesquisa-ação objetiva transcender a teoria, apresentando soluções plausíveis para problemas reais. Assim, quando nos referimos a Educação Inclusiva como objeto de pesquisa, o propósito da pesquisa-ação é justamente promover a garantia de direitos, provocar reflexões acerca das dificuldades encontradas pelos alunos com necessidades educacionais específicas, reflexões sobre as práticas e metodologias usadas no ensino desse público e consequentemente melhorias no processo formativo e educacional desses alunos, promovendo assim, melhorias na formação docente, nas práticas inclusivas e na construção de uma sociedade mais justa e igualitária, que respeite os direitos e as diferenças do outro.

Assim, reafirmamos que a pesquisa-ação pode e deve funcionar como uma metodologia de pesquisa, que possibilite a construção de novos conhecimentos e ainda forme sujeitos pesquisadores, críticos e reflexivos, que vislumbrem uma educação de qualidade a todos e para todos.

\section{REFERÊNCIAS}

ANDRÉ, MARLI. Pesquisa em Educação: Buscando Rigor e Qualidade. Revista: Cadernos de Pesquisa, n.113 p. 51-64, julho/2001.

BARBIER, René. A pesquisa-ação. Série Pesquisa em educação. v.3. Trad. Lucie Didio. Brasília: Liber Livro, 2002.

BRASIL. Constituição da República Federativa do Brasil de 1988. Disponível em: http://www.planalto.gov.br/ccivil_03/constituicao/constituicao .htm Acesso em: 04 ago 2021.

CARVALHO, Rosita Edler. Educação Inclusiva com os Pingos nos Is. 2. ed. Porto Alegre: Mediação, 2004.

FRANCO, Maria Amélia Santoro. Pedagogia da Pesquisa-ação. Revista: Educação e Pesquisa, São Paulo, v. 31, n. 3, p. 483-502, set./dez. 2005. 
MANTOAN, Maria Teresa Eglér. Inclusão Escolar: O que é? Por quê? Como fazer? São Paulo: Moderna, 2003.

MANTOAN, Maria Teresa Eglér. Inclusão é o privilégio de conviver com as diferenças. In: Revista Nova Escola. Edição 182 - mai/2005.

MENEZES, E.T; SANTOS, T.H dos. Verbete Declaração de Salamanca. Dicionário Interativo da Educação Brasileira - Educabrasil. São Paulo: Midiamix, 2001. Disponível em: <http://www.educabrasil.com.br/declaracao-de-salamanca/>. Acesso em: 07 ago 2021.

SASSAKI, Romeu Kazumi. Paradigma da Inclusão e suas implicações educacionais. Revista Fórum, 2002. Disponível em: http://seer.ines.gov.br/index.php/revistaforum/article/view/1129. Acesso em 07 ago 2021.

SHÖN, Donald. Educando o profissional reflexivo: um novo design para o ensino e a aprendizagem. Porto Alegre: Artmed, 2000.

THIOLLENT, Michel. Metodologia da Pesquisa-ação. 18 a ed. São Paulo: Cortez, 2011.

TRIPP, David. Pesquisa-ação: uma introdução metodológica. Revista: Educação e Pesquisa, São Paulo, v. 31, n. 3, p. 443-466, set./dez. 2005.

\section{Recebido em: 05/01/2022}

Aprovado em: 08/02/2022 